TABLE IV-Opinions of clinical students $(n=144) .($ From Bruhn and Parsons)

\begin{tabular}{lcccr}
\hline \multicolumn{1}{c}{ Characterisation } & Surgeon & Internist & Psychiatrist & GP \\
\hline Domineering and arrogant & 90 & 5 & 3 & 1 \\
Aggressive and full of energy & 53 & 11 & 1 & 36 \\
Deeply interested in intellectual & 2 & 40 & 57 & 1 \\
$\quad$ problems & 0 & 8 & 15 & 77 \\
Deeply interested in people & 10 & 8 & 73 & 9 \\
Confused thinker & 14 & 4 & 77 & 4 \\
Emotionally unstable & 4 & 24 & 31 & 41 \\
Extremely patient & 0 & 13 & 6 & 81 \\
Friendly, pleasing personality & 3 & 65 & 5 & 27 \\
\hline $\begin{array}{l}\text { Sensitive to a wide range of factors } \\
\text { when evaluating a medical problem }\end{array}$ & 3 & & & \\
\hline
\end{tabular}

The same question was put to the students in 1976, just before their final examinations, though by then only 123 of them remained, the rest having left the medical school or stayed down a year to take a BSc degree. During the undergraduate course the students had been in contact with many surgeons, physicians, psychiatrists, and general practitioners; there had been ample opportunity for them to modify their views to fit reality, and changes were only to be expected. The responses, again in percentages, are shown in table II. There were a few changes, but the most striking feature is the similarity to the earlier opinions-so much so that no test for statistical significance is necessary. Either the stereotypes were impervious to reality or else they reflected it.

The study of Bruhn and Parsons was cross-sectional; they combined the responses of first and second year preclinical students and also of third and fourth year clinical students. Their question was almost identical, and their most comparable results are shown in tables III and IV, again as percentages. They noted that "No opinion" responses averaged 6-7\% per item and were excluded from analysis.

No comment seems to be necessary.

\section{References}

${ }^{1}$ Myers IB, Davis JA. Relation of medical students' psychological type to their specialties twelve years later. Los Angeles: Americal Psychological Association, 1964. (Obtainable from National Foundation for Educational Research, Windsor.)

${ }^{2}$ Becker HS, Geer B, Hughes EC, Strauss AL. Boys in white. Chicago: University of Chicago Press, 1961.

${ }^{3}$ Bruhn JG, Parsons OA. Medical student attitudes toward four medical specialties. F Med Educ 1964 ;39:40-9.

(Accepted 23 September 1981)

\title{
Tertiary Educational Assessment with Mean Individual Level Knowledge
}

\author{
C A SHANKS, J D PAULL
}

\begin{abstract}
It is proposed that Tertiary Educational Assessment should be made using a Curve-Unifying Paradigm with its Scientific And Ultra-Conservative Experiment Ratio. Central Ranking Evaluation And Marking was used to process examination results, generating the Mean Individual Level Knowledge for the group. The concept of MILK grew from the need to encourage the average examination candidate and with it came the need for a Judgmental Understanding Goal. The results of some candidates required further handling by the addition of Student's Universal Grade Averaging Regimen.
\end{abstract}

\section{Introduction}

The marking of written examination papers climbed to new heights when the Random Assessment by Projected Examination Scripts (RAPES) was compared with well-established but labour-intensive conventional methods. ${ }^{1}$ This study confirmed that the projection of candidates' scripts down flights of stairs was as effective a method of assessment as was the conventional system for the subjective marking of essay questions

Royal Prince Alfred Hospital, Sydney, NSW 2050, Australia

C A SHANKS, MD, FFARACS, staff anaesthetist (present address: Department of Anaesthetics, the Medical School, Northwestern University, Chicago, Illinois, 60611, USA)

Department of Anaesthetics, Royal Women's Hospital, Melbourne, Victoria 3053, Australia

J D PAULL, MB, FFARACS, director
(CONVENT). The bulk of candidates fared equally well with both techniques, and the time-saving RAPES method eliminated any subjective bias on the part of the examiners. Nevertheless, several candidates who excelled with the CONVENT did poorly with RAPES and vice versa. As Number Utilising Neophytes we were used to CONVENT methods and sought to try RAPES, only to confirm the problem of those outside two deviations from the norm. Extension of the method to other examination techniques-for example, orals-disclosed further problems.

Consequently, we decided to assess the effects of a Mean Individual Level Knowledge Yardstick, Which Averaging Years, emphasises the score of the mediocre candidates, thereby providing them with a much-needed ego-boost.

\section{Method}

Attachment of the Traditional Education And Training to an Upper Decile Discrimination Excellence Rating was seen to cause our problem of non-normal candidates. This was rectified by using a Paralogical Averaging Plateau, a statistical manipulation that also produces a steep downward curve in the final marks of those candidates at the extremes. The candidates in the middle then benefited from the Central Ranking Evaluation And Marking by exhibiting acceptable Mean Individual Level Knowledge.

The concept of MILK came from the need of the average candidate to receive a Critical And Rational Teaching Of Necessities in addition to a Judgmental Understanding Goal. Thus the storage and retrieval techniques could avoid turning Mean Individual Level Knowledge Standardisations On Unsound Ranking.

The system was tested by a Clinically Heuristic End-Excluding Stochastic Examination in conjunction with Conventional Unadaptable Ranking Devices (CONVENT, above). The Weighted Holistic Examination Yield was assessed by the Positive Health In Life And 


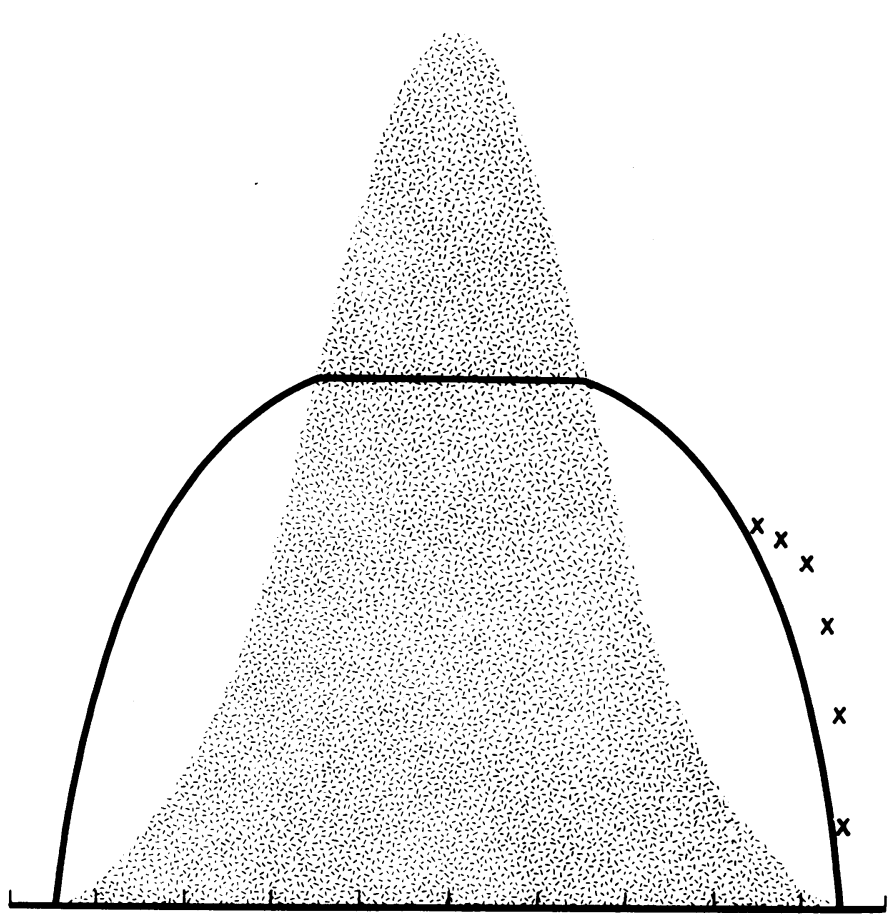

Results with the Curve-Unifying Paradigm. A normal distribution curve (shaded) was truncated at one standard deviation either side of the mean Beyond 1 standard deviation the remainder of the curve was inverted. For further details see text.

Develop Each Lowly Pattern However Insignificant Associationthat is, MILK standards were obtained from PHILADELPHIA CREAM CHEESE.

\section{Results}

The new marking system results in an almost symmetrical plot, which has been described by a Curve-Unifying Paradigm (figure). The secondary curve to the right resulted from candidates whose Symbolic Points In Linearly Tested MILK could not be removed by use of Weight-Assigned Theoretical Exponential Rectification. Further curve-smoothing by addition of a Scientific And Ultra-Conservative Experiment Ratio improved the confidence limits when handled by the modified tea test, Student's Universal Grade Averaging Regimen.

\section{Discussion}

Tertiary Educational Assessment has many forms, including Integrated Cognitive Experiential Discussion and LearningEnabled Mental Objective Numeration. In discussing options with other educators at a recent morning seminar, however, most still chose Herd-Orientated Traditional TEA with Time On Assessed Subservient Tasks. Several also expressed a strong additional preference for Mensural And Rationalised Managerial Algorithms Labelling All Distinguishing Echelons, appalling us with their disinterest and lack of behavioural modification.

While recognising that it may not suit the tastes of all decisionmaking groups we recommend that TEA should now include MILK with SUGAR.

\section{Reference}

' Longmore RB, McRae DA. Random assessment by projected examination scripts (RAPES): a new look at examination marking. $\mathrm{Br} \mathrm{Med} F \mathrm{f1979}$; ii: $1640-1$.

(Accepted 16 September 1981)

\section{The road through Oxiana, 1978}

\section{B MILSTED}

He called it his magic teapot because it never ran dry and certainly it seemed that however many people crowded into his tiny leatherware shop (fig 1) there was tea for everyone and a little left over for himself. He was as tiny as his shop, and as we drank he talked of his life and of his country Afghanistan. He sought our approval of his latest designs for sandals, belts, and bags and showed us somewhat balefully an enormous pair of leather shoes made for a traveller who had never returned to collect them. After an evening of much good humour we left, promising to return the following evening for more tea and to search diligently meanwhile for a prospective purchaser with large feet. We returned to our hotel to find the proprietor engaged in stuffing the sole of his right sandal with cannabis ready for a forthcoming trip to London. After some discussion I pointed out to him that if he walked through Heathrow with a pronounced limp in open sandals at the height of the English winter he would be unlikely to reach the far end of the customs hall a free man. He seemed genuinely grateful for this information and was deep in thought when I retired to bed.

Bearsden, Glasgow G61 4JT

B MILSTED, MD, FRCP, senior registrar
Although it is fairly remote, being a few miles from the border with Iran, the difficulty with Herat was not so much getting there as ever finding the energy or enthusiasm to leave. Certainly it took two hours for the bank to change a traveller's cheque, but that was compensated for by the pleasure of browsing in the many shops and taking multiple cups of tea with the various proprietors. The most expensive hotel room cost $f_{1}$ a night and a good meal could be had for considerably less. Occasionally local tribesmen would ride into town, turbaned and dressed in white, carrying ancient rifles, and looking like something out of a rather elegant Asian version of High Noon.

To the north of Herat lay mountains and to the south and east was desert. On the west side of the town were six ancient minarets. There would be 12 but for Eldred Pottinger. My own view is that he was a secret agent in the employ of the British Government. The official line, however, is that he was a civil servant who decided to spend his leave in search of adventure. Either way, in 1870 he dressed himself in native costume and rode across Afghanistan on a camel, arriving in Herat to find the Persian army advancing on the town. He organised the town's defences, restored the only cannon, and, finding the minarets in his line of sight, demolished half of them. The Persians wilted under the unexpected artillery barrage and 